\title{
Turkey: Health Justice and a Front-Line State
}

\author{
Steven H. MILESa
}

Turkey is a front-line state on a world war. The world war is not what the west likes to call a war on terrorism. It is a global network of active combat, failed states, and governmental duplicity.The military fronts run through Iraq, Syria, Pakistan, Afghanistan, Yemen, Somalia, and North Africa. There are raids in parts of the former Soviet States, Western Europe and the United States.

International humanitarian organizations speak of this situation as a Complex Emergency (1). A Complex Emergency is characterized by a complete breakdown in governance and civil infrastructure, population displacements, mass starvation war crimes and political violence. Humanitarian aid is seen as politically aligned and is targeted for harm or hindered by authorities. CITE Complex Emergencies reveal the failure of both will and capacity of International Organizations to restore order or render aid.

These disasters often erupt in regional epicenters of poverty. They tend to be encircled by front line states that do not have the resources to meet the extraordinary human needs of a Complex Emergency. These needs include building refugee camps, importing massive amounts of food and creating a food distribution system to the displaced persons and creating special feeding for persons with special needs, creating sanitation systems, arranging water supplies, housing displaced persons, processing persons for asylum and orderly departure programs, caring for orphans, uniting split families: an infinity of needs.

This paper considers a few issues related to the role of medical leadership for meeting the health needs of persons affected by Complex Emergencies. Medical leaders must serve as advocates for the clinical and public health system which includes food and basic shelter. At a fundamental policy level, they must forcefully argue against policies that make humanitarian aid contingent of blocking transits or influxes of displaced persons. Such transits are difficult, if not impossible, and in any case are far outsider the tools available to medical and public health workers.

\section{Medical systems in chaotic camps}

Clinical and public health systems require some degree of security in order to operate. Factional and sectarian differences within the camps fosters disputes and fights that can directly endanger persons with medical or public health needs or endanger relief personnel and operations. In addition, a perceived political or sectarian favoritism in terms of selecting beneficiaries of health care or in terms of empowering refugee employees may fuel jealousy attacks and sabotage. It falls to NGO leadership to promote security and impartiality. For example, NGO leaders must hire refugee staff equitably from all ethnic groups without discrimination.

Refugee settlements do not have much in the way of policing to handle intramural camp security. The international organization's security system focuses on protecting or evacuating humanitarian aid workers. NGO leaders must creatively promote their human services with cordial firmness. They should meet at least weekly for coffee or meals with ethnic camp leaders from all factions. They must emphasize that any fight, rape, assault on the premises of a hospital will be interpreted as an attack on the relief system as a whole that may results in an instant shut down for a day so that dialogue may occur and order be restored. Accountability for security on hospital premises cannot rely on arrests, courts and trials. The stature of camp sectarian leaders rests to a considerable degree their ability to ensure the provision of human services. That stature should be leveraged to secure safe environments in hospitals and clinics.

Refugee camps are a bewildering hodgepodge of personnel and organizations. In addition, there is valuable medical and nursing expertise in the refugee population. Variations in treatment protocols are costly, inefficient, and complicate training of community health workers to assume part of the huge

\footnotetext{
a Maas Family Foundation Chair in Bioethics, University of Minnesota $\bowtie$ miles001@umn.edu
} 
demand for treatment. It is essential and should be readily possible for the supervising international health organization to impose discipline on the treatment operations by creating brief treatment protocols that provide rapid treatment for acute illnesses and diagnose but do not start non-sustainable treatment of chronic diseases such as hypertension or diabetes. Access to international medication dispensaries should be contingent on and NGO making a commitment to comply with these protocols. International experts should be called in to create algorithms for diagnosing and managing common conditions that are new to the medical humanitarian groups responding to the Complex Emergency.

\section{Scarcity: A Problem for refugees and for front line citizens}

The front line states of Jordan, Lebanon, Turkey, Israel, and Iraq do not have the resources to handle the influx of refugees. Donors make pledges that are under-filled too late (2). The front line host states for displaced persons are not only on the dangerous brink of war but are also front line to facing an avalanche of humanitarian needs.

The front line states to this war have performed heroically and demonstrated extraordinary generosity. Turkey, Jordan, Lebanon have accepted enormous numbers of refugees. The official counts of refugees who have entered these nations are hopelessly low and become even more inaccurate as new refugees pour in. Turkey, for example, is estimated to have accepted two million Syrians, (half are children) in addition to persons from Afghanistan, Iraq and Iran (3). However, in addition to that heroic accommodation, perhaps another two or three million displaced persons have fled the war in Syria and are encamped on the threshold into Turkey. Additional mass movements can neither be predicted nor stopped. In many areas, severely limited aid rations are cut as the demand outstrips the donations.

Turkey has allowed about twenty-five of the best-designed refugee camps in the world to be built within her borders. But, as in most of the front-line states, perhaps a third of the displaced persons live in Turkey's cities and towns rather than in camps. Thus, refugees do not contribute to the host country economy as an externally funded welfare service industry but their unmet needs commingle with, and amplify, strains on the Turkish economy. The enormous influx of persons creates a toxic combination of extreme housing inflation, rising unemployment and falling wages (4). The cost of food for Turkish citizens inflates as the food needs of refugees strain and outstrips the capacity of indigenous Turkish agriculture. In some areas, Jordan comes to mind, high refugee populations can cause water tables to fall, further damaging agricultural output (5).

\section{Priorities for rationing health aid}

The external community and its media do not adequately respond to the adverse effects of a Complex Emergency on the needs of citizens of the front line states. There are minimal pledges to provide a modicum of aid to "affected communities," to address the jealousy and political rage of local villagers and urban dwellers who resent the special services to and adverse impacts of the influx of refugees and displaced persons. In general, however, front line states are expected to manage their own populations without taking account of the adverse effects on those populations that is caused by the neighboring complex emergency.

The frames of justice for considering priorities for resources are distorted when the needs of displaced populations in externally funded and sequestered camps are treated as separate from the needs of local population. It is not as simple as simple in-the-camp compared to the Turkish health care plan comparisons such as, "It is not fair refugees in the camps are given prosthetic legs through NGOs while Turkish nationals must use crutches for many months?" It is not as simple as proposing some simple way to ration the inadequate resources in refugee camps to meet the needs of a people in a destitute country. External donors are rarely responsive to pleas based on such differences are unfair. The issue of justice for front line communities relative to the servicing of front line host state populations is inseparable from the question of how to prioritize the common needs that unite these populations.

It is useful to separately consider health care justice as it applies to clinical and public health care systems for displaced persons and for locally affected communities. (See Table 1.) 
Table 1. A template for clinical and public health resource allocation for

\begin{tabular}{|c|c|c|}
\hline & Displaced Persons & Affected Frontline Host \\
\hline & Aid Dependent & Nations / Communities \\
\hline \multirow{5}{*}{ Public Health Services } & \multicolumn{2}{|l|}{ Justice as Parity } \\
\hline & \multicolumn{2}{|l|}{ Food Sanitation } \\
\hline & \multicolumn{2}{|l|}{ Water Supply } \\
\hline & \multicolumn{2}{|c|}{ Control of Vectors for Communicable Diseases } \\
\hline & \multicolumn{2}{|c|}{ Treatment \& Prophylaxis of Devastating Epidemic Diseases (TB, HIV) } \\
\hline \multirow{5}{*}{ Clinical Services } & Aid Availability & \multirow{5}{*}{$\begin{array}{l}\text { National health policy } \\
\text { As provided for by public and private } \\
\text { health infrastructure. }\end{array}$} \\
\hline & Customary: Basic Primary Care and & \\
\hline & First Aid & \\
\hline & As funded: Surgery, Prosthesis, & \\
\hline & Complex mental health services. & \\
\hline \multirow{5}{*}{ Reproductive Health Care } & International Organizations' & Local Culture \\
\hline & and Donors' Policy & Morals and Policy \\
\hline & Emergency Contraception & Emergency Contraception \\
\hline & Routine Contraception & Routine Contraception \\
\hline & Abortion & Abortion \\
\hline
\end{tabular}

Public health programs affect the entire population-those in refugee camps and refugees who live dispersed in the towns and cities of host front line nations. Public health programs are by far the most cost-effective and powerful health programming to prevent death, sickness, and disability. They improve the economic productivity of displaced persons and host nation citizens alike. It is easy to show that nonpotable water, failed sanitation systems, insect vectors, lack of vaccinations, or the failure to prevent the spread of tuberculosis or HIV affects the regional interests of refugees and host nation citizen alike. Tuberculosis and HIV delay or prevent resettlement in third countries. Failed public health to refugees quickly affects the domestic population;the reverse is also true.

For all these reasons, front-line host states are more than justified in pressuring donor nations to equitably support addressing public health issues in areas with high populations of displaced persons (regardless of camp habitation) and to host-citizens. International organizations should define these issues as falling within the ambit of the complex emergency. Given the importance, cost efficiency of public health interventions and the shortfalls in humanitarian health funding for Complex Emergencies and front-line health states, a host country should consider informing the international community that functional parity in public health infrastructure is a prerequisite to facilitating the development of infrastructure for clinical services to displaced persons. Such parity would include immunization programs, regional sanitation programs, development of sustainable water programs, screening and effective treatment of tuberculosis, prophylaxis against perinatal HIV transmission, etc.

Clinical programs are labor intensive and benefit individuals—one at a time. The telling of individual clinical stories is a powerful media tool for raising public awareness of a problem and to mobilizing donors. However, there is a serious justice issue is raised when urban refugees who not in camps or settlements seek health care in the clinical facilities used by front line host country citizens (6). It is easy to imagine how a Turkish city with several hundred thousand refugees living in close quarters in the city, could overwhelm the capacity of clinics, emergency rooms, and complex trauma services. Federal policy must cap allocation to clinical care to non-citizens however taking care that such caps are directly tied to reallocating such resources funds to public health infrastructure and programming to benefit its nationals and displaced persons alike. The international community, under the reasoning discussed for public health programming, should be informed that clinical capacity for meeting the needs of urban refugees will only be expanded as parity in public health programming is achieved. 
Finally, we come to reproductive health care, specifically emergency post-coital contraception, routine contraception and abortion services. Policies for Turkish nationals must of course follow Turkish laws and values. More flexibility is needed in refugee camps where reproductive needs are subordinated to the moral priorities of persons who do not live in the camps. Many sectarian agencies will not provide birth control. Likewise, international organizations, fearful of public controversy or pressure from donors, do not supply reproductive health programming. As a result, birth rates in refugee camps of Syrians are tenfold higher than in the host country (7). Anti-contraceptive morality that tacitly accepts extraordinary rates of neonatal death rates in under-resourced refugee populations is another aspect of the cold calculus of humanitarianism.

\section{References}

1. International Federation of Red Cross and Red Crescent Societies. Complex Emergencies. http://www.ifrc.org/en/what-we-do/disaster-management/about-disasters/definition-ofhazard/complex-emergencies/

2. United Nations High Commissioner for Refugees. UN agencies and partners say funding shortage leaves Syrian refugees and host nations without vital support. June 25, 2015. http://www.unhcr.org/558ac8829.html

3. United Nations High Commissioner for Refugees. Turkey: Country operations profile. 2015 http://www.unhcr.org/pages/49e48e0fa7f.html

4. Maza C. In Turkey, Syria's Urban Refugees Struggle to Make Ends Meet. Muftah. Oct 3, 2014. http://muftah.org/turkey-syria-urban-refugees/\#.VruSIJMrKLI

5. Water Security In Refugee Host Communities: Syrian Refugees In Jordan By Brett R. Barkley University Of Illinois At Urbana-Champaign, 2015.

Https://Www.Ideals.Illinois.Edu/Bitstream/Handle/2142/78436/Barkley-Thesis2015.Pdf?Sequence $=1$

6. Center for Middle Easter Strategic Studies. Effects of the Syrian Refugees on Turkey. ORSAM Report No: 195 January 2015.

7. Ahmad Abu Slaih. Impact of Syrian Refugees on Jordan's Health Sector Presentation Jordan Marrakesh 3-8 Dec 2013 